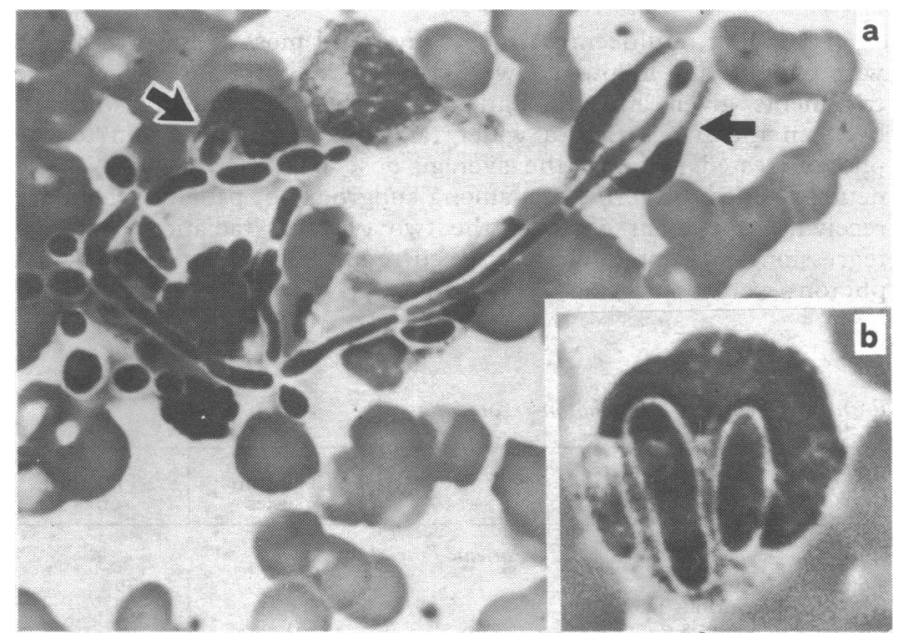

Candida pseudohyphae and blastospores in blood smear (Wright's stain; (a) $\times 325,(b) \times 651)$. (a) There are at least six neutrophils around pseudohyphae phagocytizing fungal elements are seen (arrows). (b) Pseudohyphae in a neutrophil. The clear space surrounding the basophilic organisms represents the cell wall, which does not take Wright's stain.

of candidaemia. ${ }^{2}$ Strikingly, the microscopical examination of the blood smears prepared by a widely used laboratory method disclosed the first evidence of candidaemia, and, because of the rapid diagnosis, we could start treatment only a few hours after fever began, which was his first symptom of the infection. Candida has also been seen in blood smears in three other reported $\operatorname{cases}^{34}$ and this method of diagnosis needs to be considered in a possible case. Fever is the most common symptom in candidaemia, ${ }^{2}$ and, since Candida blastospores and pseudopyphae are phagocytosed by leucocytes (and therefore their number may be diminished by destruction), the blood smears should be prepared at the time the temperature rises, as we did in this patient.

We thank Mr A Regenass for the haematological investigations.

Requests for reprints should be addressed to Dr K Kobza, Spezialarzt für Innere Medizin FMH, Trottenwiesenstrasse 2, 8404 Winterthur, Switzerland.

${ }^{1}$ British Medical fournal, 1975, 3, 264.

2 Kobza, K, et al, Lancet, 1976, 2, 1084.

${ }^{3}$ Portnoy, J, et al, New England fournal of Medicine, 1971, 285, 1010.

4 Silvermann, E M, et al, American fournal of Clinical Pathology, 1973, 60, 473 .

(Accepted 7 March 1977)

University of Basle, Kantonsspital Basel, Switzerland

$\mathrm{K}$ KOBZA, MD, resident, department of medicine

U STEENBLOCK, MD, chief resident, department of surgery

\section{Effect of wholemeal and white bread on iron absorption in normal people}

Two aspects for consideration in studies of bread and iron absorption are the effect of bread on absorption of dietary iron and the relative merits of wholemeal and white bread as sources of iron. Reports on iron absorption from bread ${ }^{1-4}$ are conflicting, but none of the recent ones $^{2-4}$ have compared absorption of iron from white and wholemeal bread in the same person. It is important to determine the effect of dietary fibre on iron absorption because of the popularity of highfibre diets. We report a comparison of the effects of both white and wholemeal bread on the absorption of physiological amounts of iron in 13 normal subjects.

\section{Subjects, methods, and results}

The subjects were healthy, non-anaemic (haemoglobin $>12 \mathrm{~g} / \mathrm{dl}$ in women and $13.8 \mathrm{~g} / \mathrm{dl}$ in men) volunteers from an obesity clinic who were taking a $3.3 \mathrm{MJ}(800 \mathrm{k} \mathrm{cal})$ diet. The bread was given as a standard meal after a 12-hour fast. No tea or coffee was drunk for 12 hours after the meal. No subject had blood loss, or took aspirin or iron treatment during the study. Eight of the nine women were postmenopausal, the other having had a hysterectomy.

The iron was given as $5 \mu \mathrm{Ci}^{59} \mathrm{Fe} \mathrm{Cl}_{3}$ in solution with $250 \mathrm{ml}$ distilled water, and the meal consisted of $100 \pm 5 \mathrm{~g}$ of wholemeal or white bread. Both breads were made from the same batch of Manitoba flour, the wholemeal being of higher extraction, and the white was not supplemented with iron. In addition to the two types of bread, the subjects received a third test containing the same amount of iron with $100 \mathrm{mg}$ ascorbic acid as fresh orange juice.

The absorption of ${ }^{59} \mathrm{Fe}$ was measured with a whole-body counter using a multiple-dose technique similar to that of Callender and Warner. ${ }^{2}$ Repeat counts were close at 30 minutes after the test meal, and again 48 hours later, retention being measured at 14 days. Absorption tests were given according to a random block design. Thirteen subjects volunteered so that all the six possible orders of three tests were given at least twice.

The table shows that the absorption of iron with wholemeal bread was significantly less than with white bread $(P<0.01)$. Ascorbic acid enhanced absorption in all but one subject. Analysis of variance confirmed a difference between treatments $(P=0.002)$ and showed no significant difference between the orders in which the treatments were given $(P=0.16)$ or any significant interactions $(P=0.99)$.

Effect of orange juice, wholemeal, and white bread on absorption of iron

\begin{tabular}{|c|c|c|c|c|c|}
\hline \multirow[b]{2}{*}{ No } & \multirow[b]{2}{*}{ Sex } & \multirow[b]{2}{*}{$\begin{array}{c}\text { Age } \\
\text { (yrs) }\end{array}$} & \multicolumn{3}{|c|}{ Iron absorption $(0,0) *$} \\
\hline & & & $\begin{array}{l}\text { Orange juice } \\
\text { (OJ) }\end{array}$ & $\begin{array}{l}\text { White bread } \\
\text { (WB) }\end{array}$ & $\begin{array}{l}\text { Wholemeal bread } \\
\text { (BB) }\end{array}$ \\
\hline $\begin{array}{r}1 \\
2 \\
3 \\
4 \\
5 \\
6 \\
7 \\
8 \\
9 \\
10 \\
11 \\
12 \\
13\end{array}$ & $\begin{array}{c}M \\
\mathbf{F} \\
\mathbf{F} \\
\mathbf{F} \\
\mathbf{F} \\
\mathbf{F} \\
\mathbf{M} \\
\mathbf{M} \\
\mathbf{F} \\
\mathbf{F} \\
\mathrm{F} \\
\mathbf{M} \\
\mathbf{F}\end{array}$ & $\begin{array}{l}\mathbf{4 4} \\
52 \\
62 \\
52 \\
35 \\
41 \\
50 \\
56 \\
62 \\
71 \\
57 \\
47 \\
54\end{array}$ & $\begin{array}{r}10.3 \\
41.9 \\
5.6 \\
21.0 \\
30.2 \\
20.6 \\
9.9 \\
1.1 \\
17.0 \\
19.0 \\
20.1 \\
42.9 \\
9.5\end{array}$ & $\begin{array}{r}1.2 \\
25.2 \\
2.7 \\
7.2 \\
19.9 \\
16.6 \\
0.0 \\
0.0 \\
2.6 \\
5.3 \\
4.9 \\
19.5 \\
5.5\end{array}$ & $\begin{array}{r}0.0 \\
6.0 \\
0.5 \\
0.0 \\
0.1 \\
0.0 \\
0.0 \\
0.5 \\
0.2 \\
1.4 \\
0.4 \\
27.4 \\
0.3\end{array}$ \\
\hline \multicolumn{3}{|c|}{ Mean \pm ISEM } & $19.16 \pm 3.58$ & $8.51 \pm 2 \cdot 39$ & $2 \cdot 81 \pm 2 \cdot 07$ \\
\hline
\end{tabular}

Paired $t$ tests $(\mathrm{DF}=12$ ) showed: OJ $v$ WB, $t=5.97 ; \mathrm{P}=0.0001 ; \mathrm{OJ} v \mathrm{BB}, t=$ $6.08 ; \mathrm{P}=0.0001 ; \mathrm{WB}^{2} \mathrm{BB}, t=2.52, \mathrm{P}=0.01$.
*Iron given as $5 \mu \mathrm{Ci}^{5} \mathrm{Fe} \mathrm{Cl}_{3}$ in $250 \mathrm{ml}$ distilled water.

\section{Discussion}

We used small amounts of inorganic iron labelled with ${ }^{59} \mathrm{Fe}$ as an "extrinsic tag" to study the effects of fibre on dietary iron, wholemeal bread being used as a high-fibre meal and white bread as a low-fibre meal. Layrisse and Martinez-Torres ${ }^{5}$ showed a high correlation between the absorption of extrinsic tag given with the food of native iron biosynthetically labelled ("intrinsic tag") in vegetable food. They postulated that the extrinsic iron mixes with the non-haem iron pool and may be used as a marker for non-haem iron in food. Orange juice, containing about $100 \mathrm{mg}$ ascorbic acid, was added to the iron to measure "augmented" iron absorption. ${ }^{3}$ Other dietary factors such as eggs and tea, which inhibit iron absorption, were avoided on test days.

Our results confirm that wholemeal bread significantly inhibits the absorption of non-haem iron. Iron may be rendered less available for absorption by constituents of the wholemeal, such as phytate. ${ }^{1}$ The over-enthusiastic consumption of bran-for example, in breakfast cereals-may increase the long-term risk of iron deficiency by inducing negative balance. Vegetarians tend to eat wholemeal bread rather than white and this may inhibit iron absorption. They are also deprived of haem iron, which is an important source and doubles the absorption of vegetable iron. ${ }^{5}$ If other types of fibre inhibit the absorption of nonhaem iron, a high-fibre diet taken over long periods may cause negative iron balance and encourage the development of anaemia, particularly if there is associated chronic blood loss, as in diverticular disease.

Wholemeal flour contains more iron than white bread. The iron content of white bread is supplemented with iron to bring it to that of $80 \%$ extraction flour. According to the Layrisse/Martinez-Torres model $^{5}$ the extrinsic iron mixes with that of bread and acts as a label 
for it. Since wholemeal Manitoba flour contains 3.8 to $3.9 \mathrm{mg}$ iron/ $100 \mathrm{~g}$, compared with $1 \mathrm{mg} / 100 \mathrm{~g}$, in unsupplemented white bread, the amounts of iron absorbed from both types of bread are similar $(0.11 \mathrm{mg} / 100 \mathrm{~g}$ from wholemeal and $0.09 \mathrm{mg} / 100 \mathrm{~g}$ from white flour). Further isotopic studies are needed to determine whether supplementation of white bread with elemental iron increases the absorption of iron. We suggest that supplementation of white bread with iron may be unnecessary as the higher iron absorption compensates for the lower iron content.

We thank Dr N Fisher and Dr J B Hutchinson of the Flour Milling and Baking Research Association for supplying the flours and for helpful advice.

1 Widdowson, E M, and McCance, RA, Lancet, 1942, 1, 588.

2 Elwood, P C, et al, American fournal of Clinical Nutrition, 1968, 21, 1162.

${ }^{3}$ Callender, S T, and Warner, G T, American fournal of Clinical Nutrition, $1968,21,1170$.

4 Elwood, D A, et al, American fournal of Clinical Nutrition, 1970, 23, 1267.

${ }^{5}$ Layrisse, M, and Martinez-Torres, C, American fournal of Clinical Nutrition, 1972, 25, 401.

(Accepted 15 February 1977)

West Middlesex Hospital, Isleworth, Middlesex

R J DOBBS, MRCP, DCH, honorary senior medical registrar I MCLEAN BAIRD, MD, FRCP, physician

\section{Comment}

In this first, multicentre co-operative trial most of the treatments with photons and follow-ups were done in the hospital of origin. The treatments given and the patients' records consequently differed between the two series: a wider range of doses was given to the photon-treated patients, the average dose being lower than in the neutron series. Nevertheless, among subgroups of patients who were receiving equivalent doses of the two types of radiation complete regression of tumour without recurrence was much rarer when photons were used.

Results in neutron- and photon-treated patients

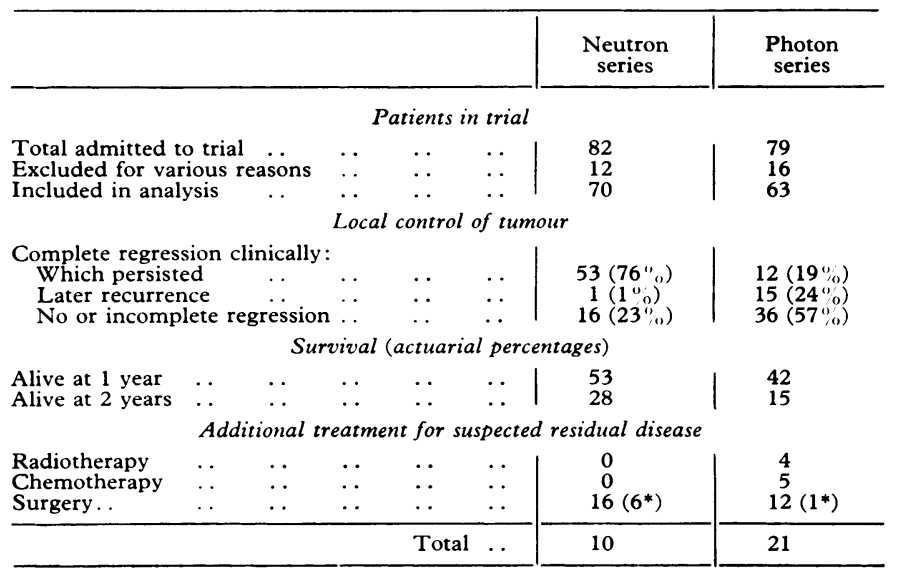

Severe complications in patients with cured tumours

Eyes

\begin{tabular}{lccccc|c|c} 
Eyes & $\ldots$ & $\ldots$ & $\ldots$ & $\ldots$ & $\ldots$ & 2 & 1 \\
Spinal cord & $\ldots$ & $\ldots$ & $\ldots$ & $\ldots$ & $\ldots$ & 2 & 1 \\
Larynx and pharynx & $\ldots$ & $\ldots$ &. & $\ldots$ & 6 & 10
\end{tabular}

\section{Second report on results of a randomised clinical trial of fast neutrons compared with $x$ or gamma rays in treatment of advanced tumours of head and neck}

Patients with advanced tumours of the head and neck were allocated at random to treatment with neutrons or photons ( $x$ or gamma rays). All except one (whose tumour was stage $T_{2} N_{1}$ ) had tumours of stage $\mathrm{T}_{3}$ or $\mathrm{T}_{4}, \mathrm{~N}_{0}, \mathrm{~N}_{1 \mathrm{~b}}, \mathrm{~N}_{2 \mathrm{~b}}$, or $\mathrm{N}_{3}$ (TNM classification 1 ). The neutrontreated patients received a standard dose of 1560 rads given in 12 treatments over four weeks, the MRC's cyclotron at Hammersmith Hospital being used. Of the photon-treated patients, $40 \%$ were treated at Hammersmith Hospital and the others at collaborating hospitals. The doses ranged from 4540 to 6840 rads over four to six weeks. Details of eligibility for the trial were reported previously together with the results in the first 107 patients. $^{2}$ The final total number of patients admitted to the trial was 161 , and we report here the results up to September 1976.

\section{Results}

The early results showed highly significant benefit to the neutron-treated patients in local control of the tumour. The present analysis, two years later, shows that this benefit has been maintained and that, with one exception, local control in the neutron series has persisted without recurrence. Further details are given in the table.

The proportions of patients whose tumours clinically completely regressed were $77 \%$ in the neutron series and $43 \%$ in the photon series. Only one tumour recurred in the neutron series, compared with 15 in the photon series. Survival was slightly better in the neutron series, but the differences were not significant. Twice as many patients in the photon series (21) as in the neutron series (10) underwent further treatment with chemotherapy radiotherapy, or surgery for suspected residual disease. Malignancy was found in only four of the 10 surgical specimens from the neutron-treated patients, compared with 11 of the 12 from those in the photon series. The number of severe complications in patients whose tumours were apparently cured was greater in the neutron series, and these were most common and most troublesome in the larynx and oropharynx. In some cases, however, the tumours may already have caused irreparable damage, which did not become evident in the photon series because of poorer local control.
Causes of death (numbers of patients)

Residual or recurrent cancer in treated site with or without metastases Metastases with treated site controlled. Complications of radiation or surgery ... Unrelated to cancer (tumour controlled)

\begin{tabular}{cc|c|c}
\multicolumn{2}{c|}{ site with } & $10(4+)$ & $44\left(4^{+}\right)$ \\
. & $\cdots$ & $13(9+)$ & 2 \\
. & $\cdots$ & $10\left(3^{*+}\right)$ & 2 \\
. & $\cdots$ & 5 & 0 \\
& $\cdots$ & $7(3+)$ & 0 \\
\hline Total &. & $45\left(19^{+}\right)$ & $48\left(4^{+}\right)$ \\
\hline
\end{tabular}

*Patients in whom no malignancy was found in surgical specimen. +Patients in whom confirmation of cause was obtained at necropsy.

In this trial the patients had such advanced tumours that death often occurred from degenerative or metastatic disease, thus making it impossible to assess the long-term effects in most patients. The encouraging results of treatment with fast neutrons suggest that it may be of long-term value to patients who have smaller tumours and are in better general condition. To investigate these long-term effects of neutron treatment a new trial has been started to compare neutrons with photons, or photons plus surgery, in patients with $T_{2}$ and $T_{3}$ tumours of the head and neck.

${ }^{1}$ International Union against Cancer, TNM-Classification of Malignant Tumours. Geneva, UICC, 1968.

2 Catterall, M, Sutherland, I, and Bewley, D K, British Medical fournal, 1975, 2, 653.

(Accepted 8 March 1977) Medical Research Council Cyclotron Unit, Hammersmith Hospital,
London W12 0HS

MARY CATTERALL, FRCR, DMRT, consultant-in-charge, fast-neutron clinic.

DAVID K BEWLEY, MA, PHD, senior physicist London WC1

IAN SUTHERLAND, DPHIL, director Uncertain (tumour controlled)

Medical Research Council Statistical Research and Services Unit, 